\title{
Application of an Anthracene Containing Polymer to a Negative Type Photoresist ${ }^{\dagger}$
}

\author{
Kỵu Ho Chae. ${ }^{*}$ Yong Woon Kim, and Taek Hỵeon Kim \\ Faculty of Applied (hemistry and The Polvmer Wience \& Technologr Research ('enter, \\ (homam Xational Iniversitv, (Jwanglu 500-757, Korea \\ Recened Fehruary 19, 2002
}

Key Words : Anthracene polymer. Photoresist. Photo-crosslinking

Photoresists are very important materials for the photofabrication process. They are widely used for the manufacture of microelectronics. printed circuit boards. silk screen printing. optical disks. black matrix of color cathodray tıbes. and so on. They can be classified into two types on the basis of the solubility changes upon irradiation with UV light. i.e. positive or negative types. The negative type of photoresist is generally more sensitive than the positive one.

It is well known that anthracene or its derivatives dimerize photochemically to give $[4+4]$ cycloadducts across the 9.10 positions of anthracene. 'and the reaction can be reversed by the shorter wavelength irradiation or by heating. " If the irradiation was carried out in the presence of oxygen, 9.10endoperoxide as well as photodimer are produced. ${ }^{3}$ These photochemical reactions of the anthracene groups in the polymer induce considerable changes in their physical properties. for instance, refractive index, absorption, or the degree of solubility etc. which enables them to apply various optoelectronic materials. ${ }^{2}$ Thus, the antluracene containing polymers have been used to develop light-switched chromic devices, ${ }^{45}$ electroluminescent devices, ${ }^{6-8}$ photoresist and channel wavegnide applications. ${ }^{p}$ and others.

We are interested in the polymers bearing antluracene (An) groups because of their versatile photoreactivity and various photonic applicabilities. A lots of papers have been reported the application of photochemical $[2+2]$ cycloaddition reactions to photoresist materials. Howerer. as far as we know. the application of $[++4]$ crcloaddition reactions as a photoresist is very rare. In this paper. we prepared a homopolymer containing oxyantluracene groups and applied it as a negative type photoresist.

\section{Experimental Section}

Matrials and instruments. 6-Bromo-1-hexanol and methacrylic anhydride were purchased from Aldrich Chemical Company and used without further purification. Anthraquinone was obtained from Junsei Chemical Company: Anthrone was prepared by the reported procedure. "1" Irradiations were carried out on a Rayonet photochemical reactor (The Southern New England UV Company model 208) equipped

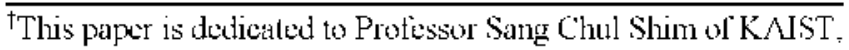
who has passed away untimely.

*Corresponding author: Phonc: +82-62-530-1874. Fas: +82-62530-1909, E-mail: thochacia chomam.ack with 365 or $254 \mathrm{~nm}$ fluorescent lamps. One module of the photochemical reactor was placed in a horizontal position and irradiated. Light intensity was measured by a Vilber Lourmat radiometer model VLX-3W. An Able model ASS301 spin coater was used for the preparation of polymer films. Micropatterns were observed by a Zeiss model Axiolab A optical microscope.

Synthesis of 6-(9-anthryloxy)hexane-1-ol (1). A mixture of anthrone $(5.00 \mathrm{~g} .25 .8 \mathrm{mmol}) . \mathrm{K}_{2} \mathrm{CO}_{3}(4.30 \mathrm{~g} .31 \mathrm{mmol})$, and 6-bromo-1-hexanol $(4.0 \mathrm{ml} .31 \mathrm{mmol})$ in acetone $(30$ $\mathrm{ml})$ was refluxed for 48 hours with stirring. The salt formed was removed by filtration from the reaction mixture. After concentration by evaporation of the solvent under reduced pressure, the product was isolated by silica gel column chromatography and purified by crystallization from petroleum ether. The yield and melting point were $35 \%(2.65 \mathrm{~g})$ and $66-68^{\circ} \mathrm{C}$. respectively.

IR (KBr pellet. $\mathrm{cm}^{-1}$ ): 3261 (s: -OH), 3051 (s: aromatic CH), 2935 (s. aliphatic C-H). 1620 (s: anthracene $\mathrm{C}=\mathrm{C}$ ). 1338 . 1085 (s: C-O-C), 739. 'H-NMR (chloroform-d. $\delta$, ppm): 8.29-7.43 (9H, m. anthracene ring), 4.20 (2H, t. Ant-O-CH-). $3.71(2 \mathrm{H} . \mathrm{ml} .-\mathrm{C} \underline{\mathrm{H}} 2-\mathrm{OH}), 2.08$ (2H. m. An- $\left.-\mathrm{O}_{2} \mathrm{CH}_{2}-\mathrm{C}_{2}-\right)$. $1.77-1.55\left(6 \mathrm{H}, \mathrm{m} . \mathrm{HO}-\mathrm{CH}_{2}-\left(\mathrm{CH}_{2}\right)_{3}-\mathrm{CH}_{2} \mathrm{CH}_{2}-\mathrm{O}-\mathrm{An}\right)$.

$\mathrm{C}_{20} \mathrm{H}_{22} \mathrm{O}_{2}(294.39)$ Calc: $\mathrm{C} 81.63 . \mathrm{H}$ 7.48. O 10.88. Found: C 81.67. H 7.43. O 10.90.

Synthesis of 6-(9-anthryloxy)hexyl methacrylate (2). Methacrylic anhydride $(0.73 \mathrm{~mL}, 4.9 \mathrm{mmol})$ in $5 \mathrm{~mL}$ of benzene was added dropwise to a mixture of compound 1 $(1.2 \mathrm{~g} .4 .1 \mathrm{~mm} 0 \mathrm{l})$. pyridine $(1.32 \mathrm{~mL} .8 .2 \mathrm{mmol})$, trietlyyannine $(2.28 \mathrm{~mL} .5 .2 \mathrm{mmol})$. hydroquinone $(3 \mathrm{mg})$, and benzene $(40 \mathrm{~mL})$, which was refluxed for 3 hours with stirring. After addition of methacrylic anlydride. the reaction mixture was refluxed for 3 days. The reaction mixture was washed with distilled water three times and was dried with $\mathrm{MgSO}_{4} . \mathrm{MgSO}_{4}$ was removed by filtration. and the filtrate was concentrated by exaporation of the solvent under reduced pressure. A yellow crystalline solid was isolated by silica gel column chromatography. The product was purified by crystallization in petroleum ether. The yield and melting point were $35 \%(0.52 \mathrm{~g})$ and $32-34$ "C. respectively.

IR ( $\mathrm{KBr}$ pellet. $\mathrm{cm}^{-1}$ ): 3044 (s: aromatic C-H), 2941 (s: aliphatic $\mathrm{C}-\mathrm{H}$ ). $172+$ (s: ester $\mathrm{C}=\mathrm{O}$ ). 1637 (s: anthracene $\mathrm{C}=\mathrm{C}$ ). $1416,1340.1088$ (s: C-O-C), 740. 'H-NMR (clloroform-d. $\delta . \mathrm{ppm}): 8.28-7.43(9 \mathrm{H}, \mathrm{m}$, anthracene ring), 6.12 . $5.55(2 \mathrm{H} . \mathrm{d}, \mathrm{C} \underline{\mathrm{H}}=\mathrm{C})+4.22-4.12\left(+\mathrm{H}, \mathrm{m} . \mathrm{C}(=\mathrm{O})-\mathrm{O}-\mathrm{Cl}_{2}-\right.$ and $\mathrm{O}-\mathrm{C} \underline{\mathrm{H}}-) .2 .07\left(2 \mathrm{H}, \mathrm{m}, \mathrm{O}-\mathrm{CH}_{2}-\underline{\mathrm{H}}_{-}-\right) .1 .95$ (3H. s. $\left.-\mathrm{C}_{3}\right)$. 
1.82-1.53 (6H. m. An-O-CH2-CH $\left.-\left(\mathrm{CH}_{2}\right)_{3}-\right)$.

$\mathrm{C}_{24} \mathrm{H}_{28} \mathrm{O}_{3}(364.48)$ Calc: $\mathrm{C} 79.56$, H 7.18. O 13.26.

Found: C 79.56. H 7.18. O 13.26 .

Preparation of PAn (3). A mixture of compound 2 (1.00 g. $2.76 \mathrm{mmol}$ ) and AJBN (9.2 mg. $2 \mathrm{molc} \%)$ in THF (5 mL) was purged with $\mathrm{N}_{2}$ gas for twenty minutes and the polymerization was carrice out at $60^{\circ} \mathrm{C}$ for iwenty hours. After concentrating the reaction mixture by exaporation of the solvent under reduced pressure. the resulting polymer was purificd by double precipitation in methanol (vicld $57 \%$ ).

IR ( $\mathrm{KBr}$ pellet. $\left.\mathrm{cm}^{-1}\right): 3051$ (aromatic $\mathrm{C}-\mathrm{H}$ ). 2939) (aliphatic $\mathrm{C}-\mathrm{H}$ ). $1724(\mathrm{C}=\mathrm{O}) .1624$ (anthracene $\mathrm{C}=\mathrm{C}$ ). 1340 ) (aromatiuc C-O). $1261.1153 .1090 .{ }^{1} \mathrm{H}-\mathrm{NMR}\left(\mathrm{CDCl}_{\mathrm{s}} \delta . \mathrm{ppm}\right): 7.2-8.4$ (9H. anthracenc). $3.8-4.2\left(4 \mathrm{H} . \mathrm{O}-\mathrm{CH}_{2}-\right), 0.8-2.2\left(13 \mathrm{H},-\mathrm{CH}_{2}-\right.$ $\left.-\mathrm{CH}_{3}\right)$.

Film preparation. A 10 wi polymer solution was prepared by dissolying PAn $(0.1 \mathrm{~g})$ in THF $(1 \mathrm{~mL})$. and it was filtered with a Milipore filter. The polymer solution was spin coated on a quart/ plate $(3.5 \times 1.3 \mathrm{~cm})$ by a spin coater with $1000 \mathrm{rpm}$ for 10 scconds at $1 \mathrm{st}$ run and $2000 \mathrm{rpm}$ for 10 seconds at 2nd run. respectively. The film on a quarty plate was dried at room temperature for l hour followed by drying at $50^{\circ} \mathrm{C}$ for 4 hours under vacuum. The film for the patern formation was prepared on a silicon waler through the same procedure except spin coating with $1500 \mathrm{rpm}$ on the lst run for 10 seconds and 3000 rpm on the 2 nd run for 10 scconds. respectively:

\section{Measurement.}

Dissolved fraction: The two PAn films on the quarty plates. one in an atmosphere of nitrogen and the other in that of air. were irradiated with $350 \mathrm{~nm}$ UV light. The irradiated films were dipped in THF (20 $\mathrm{mL})$ for $20 \mathrm{~min}$. and dricd at $50^{\circ} \mathrm{C}$ for 2 hours under reduced pressure. Dissolved fraction was calculated by the following equation (1) at the isosbestic point $(322 \mathrm{~nm})$ of the UV absorption spectra:

$$
\text { Dissolved fraction }(\%)=-\frac{A_{d}}{A_{i}} \times 100
$$

where. $A_{i}$ is an absorbance of the PAn lilm at $322 \mathrm{~nm}$ upon irradiation with $350 \mathrm{~nm}$ UV light and $A_{d}$ is that at $322 \mathrm{~nm}$ after dipping in THF.

UV absorption spectral changes: Two PAn films on the quart/ plate were prepared. One in an atmosphere of $\mathrm{N}_{2}$ and the other in an atmosphere of air were placed under the UV lamp and irradiated. UV absorption spectral changes upon irradiation with $350 \mathrm{~nm}$ UV light (light intensity: $1.6 \mathrm{~mW} /$ $\mathrm{cm}^{2}$ ) were obsericd.

Pattern formation. A PAn lilm on the silicon wafer was covered with a photomask and irradiated with $350 \mathrm{~nm}$ UV light for $20 \mathrm{~min}$. The irradiated film was dipped in $40 \mathrm{~mL}$ of THF for 20 scconds followed by drying at $50^{\circ} \mathrm{C}$ for 2 hours. The micropattern formed on the silicon wafer was observed by an optical microscope.

\section{Results and Discussion}

Recently. Schopos et $a .^{11}$ reported the preparation of compound 1. a new monomer containing anthracene group. and studied the photochemical reaction of its methacrylate copolymer. Concomitantly. we $^{12}$ have presented a synthetic route for the preparation of compound 1 and its homopolymer in different way.

Scheme I shows a synthetic route for the preparation of a monomer and a homopoly mer containing anthracene groups. Anthrone was prepared from the reduction of anthraquinone

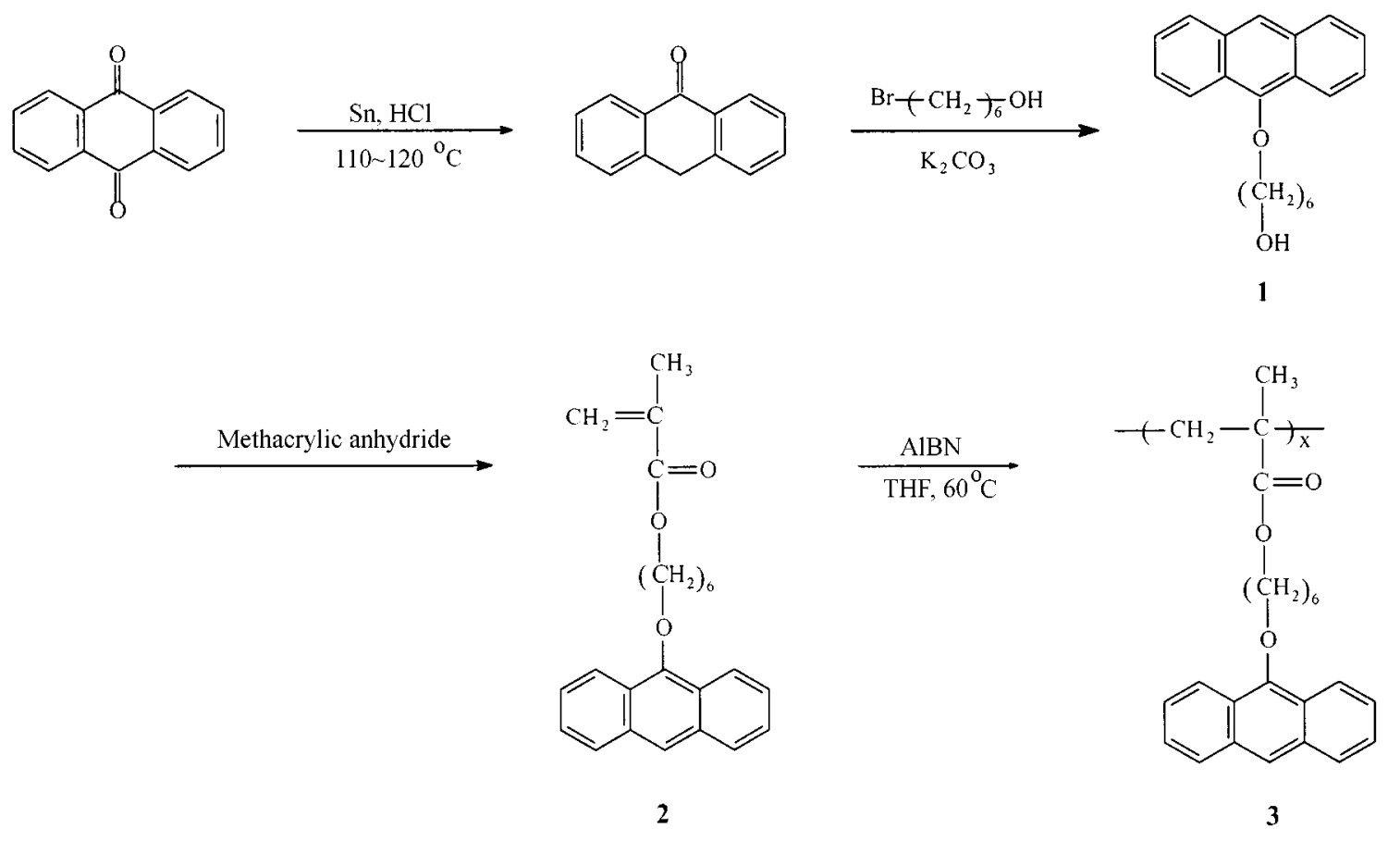

Scheme 1 
with tin. 9-Hydroxyanthracene (9-anthrol) exisis mainly anthrone duc to the keto-enol tautomerization ${ }^{13}$ and anthrone casily oxidised to anthraquinone. The compound 1 , a blue fluorescent compound. was prepared from the reaction of anthrone with 6-bromohexanol in the presence of $\mathrm{K}_{2} \mathrm{CO}_{3}$ in acclone.

Gencrally, methacrylic esters were synthesized from the reaction of methacry loyl chloride with alcohols in the presence of amine. However. anthrone and 9.10-anthraquinone were produced with the product ratio of $1: 4$, when the reaction was run with methacry loyl chloride and compound 1. This secms to be due to the hydrolysis of the compound 2 by $\mathrm{HCl}_{\text {a }}$ side product of the reaction. So. compound 2 was prepared through the reaction of compound 1 with methacrylic anhydride followed by the column chromatography and recrystallization. Compound 2 did not crystallize casily at room temperature duc to the low melting point $\left(30-32^{\circ} \mathrm{C}\right)$. Compound $\mathbf{2}$ has a blue fluorescence.

PAn. a polymer containing anthracenc groups was prepared by polymerization of compound 2 in the presence of catalytic amount of AIBN. It is soluble in DMF. DMSO. THF, and chloroform. but insoluble in methanol or cther. PAn has a good film forming property on the solid matrix. The molecular weight $(\bar{M} n)$ and poly dispersity ol' PAn were 6.300 and 1.94. respectively. The glass transition temperature $\left(T_{g}\right)$ measured by DSC and the thernal decomposition temperature $\left(T_{d}\right)$ measured by TGA were 50.6 and $300^{\circ} \mathrm{C}$. respectively. This indicates that PAn is relatively thermally slable compared with PMMA.

The polymer containing anthracenc groups undenient crosslinking through the photodimerization reaction of anthracene groups. This reaction can be applicd to a negative type of photoresist.

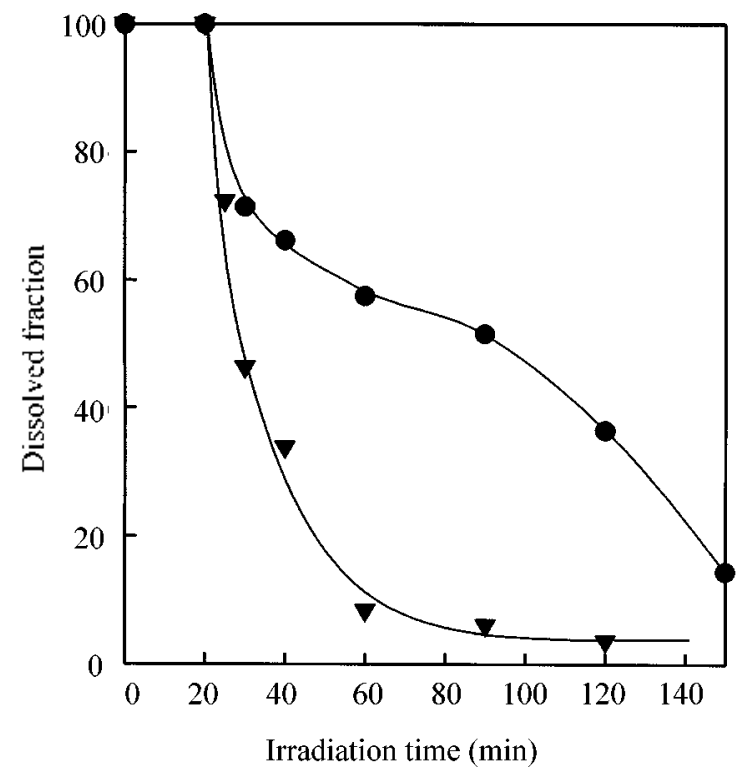

Figure 1. Plot of the dissolved fraction as a function of irradiation time of a PAn film upxon itradiation with $350 \mathrm{~mm}$ [IV light in an atmosphere of air ( $\boldsymbol{\nabla}$ ) and $\mathrm{N}_{2}$ ( $\bullet$ ). Dipping solvent: TH $\mathrm{T}$, dipping time: $20 \mathrm{sec}$
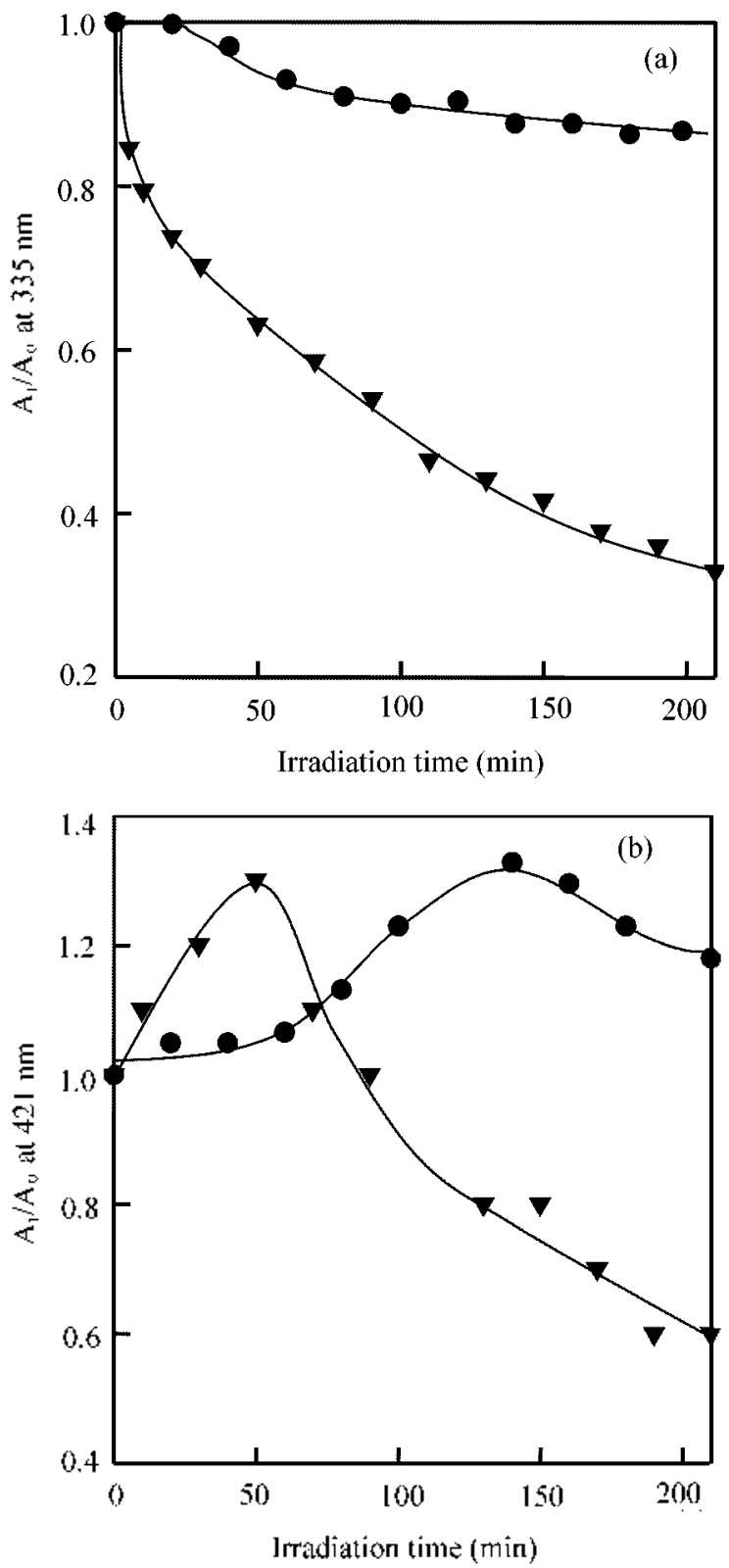

Figure 2. Plots of $1, / . i_{0}$ of a PAn lilm as a function of irradiation time at (a) $335 \mathrm{~nm}$ and $421 \mathrm{~nm}$ in an atmosphere of $\mathrm{N}_{2}(\bullet)$ and air ( $)$, respectively:

The PAn film was soluble in THF or chloroform before irradiation. while it became insoluble after irradiation. Figure 1 shows dissolved fraction of the PAn film in THF as a function of irradiation time. The dissolved fraction decreased upon irradiation with 350 un UV light as a result of photo-crosslinking. The decrease rate of the dissolved fraction in air is faster than that in $\mathrm{N}_{2}$. Thus. the photocrosslinking in an atmosphere of air is nore effective than that in an atmosphere of $\mathrm{N}_{2}$. This result indicates that photocrosslinking of the PAn was induced not only by photodimerization but also by photooxidation reaction.

In order to understand the difference in the photo-crosslinking reaction of PAn in an atmosphere of $\mathrm{N}_{2}$ or air. its photochemical reaction was studied by the UV absorption 


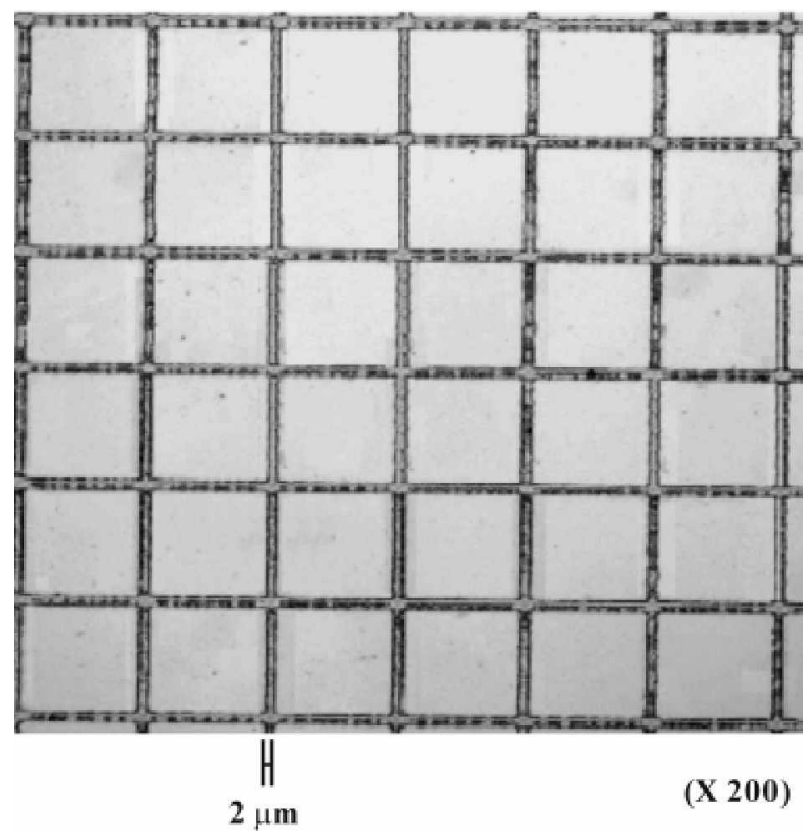

Figure 3. An optical micrograph of a negative micropalten of the PAn film on a silicon water alter irradiation of $2.1 \mathrm{~J} / \mathrm{cm}^{2}$ followed by developing in THF tor $20 \mathrm{sec}$

spectroscopy in the film state. Figure 2 shows the plot of the $A_{t} / A_{0}$ of a PAn film at (a) 335 and (b) $421 \mathrm{~nm}$ as a function of irradiation time in an atmosphere of $\mathrm{N}_{2}$ or air. The relative decrease in absorbance at $335 \mathrm{~nm} \mathrm{in}$ an atmosphere of $\mathrm{N}_{2}$ was smaller than that in air. This seems to be duc to that the photodimerization of the anthracene groups in the polymer is the only photochemical reaction in the nitrogen atmosphere. while the endoperoxide formation as well as photodimerization took place concomitantly in an atmospherc of air.

It should be noted that the absorption band at around 400( 450 m comes from the anthracene dimer that was produced by the photodimerization of anthracene. ${ }^{14}$ As shown in Figure 2(b). the absorbance ratio of the PAn film at $421 \mathrm{~nm}$ in an atmosphere of $\mathrm{N}_{2}$ increased steadily upon irradiation during $130 \mathrm{~min}$. However, in the presence of oxygen, it increased somewhat during the beginning 50 minutes of irradiation time, and then steadily decreased as a result of photooxidation.

The photolysis of anthracene in an atmosphere of $\mathrm{N}_{2}$ produces the antluracene photodimer as the only product. Irradiation in an atmosphere of air led to the formation of the photodimer as the minor photoproduct and the endoperoxide as the major photoproduct. The endoperoxide underwent thermal decomposition to produce several secondary oxidation products. ${ }^{3}$ It seems to be very likely that the photodecomposition products of anthracene endoperoxide groups in the poly mer side chain also induce cross-linking.

Figure 3 shows a texture of a line and space pattern of the PAn film on a silicon wafer. Although the cxperimental conditions were not fully optimized. the line width of the pattern with l-2 $\mu \mathrm{m}$ could be obtained. The irradiated part was insoluble in THF. while the unirradiated part was soluble in THF for negative patterning.

In conclusion. we prepared a An monomer 2 in different way comparing with the reported procedure. The homopolymer of 2. PAn, was soluble in various organic solvents and has a good film forming property on the solid matrix. The rate of decrease in the dissolyed fraction of the PAn film in an atmosphere of air was faster than that in an atmosphere of $\mathrm{N}_{2}$. This secms to be due to the photo-crosslinking of the PAn lilm. that was induced not only by the photodimerization but also by the photooxidation reaction of the anthracene groups in the polymer side chains. Thus. the PAn belaves a negative type of photoresist. A micropattern with line width of about $\mathrm{j}-2 \mu \mathrm{m}$ could be obtained after developing with THF,

Acknowledgment. This work has been supported by the Brain Korca 21 Project in 2001 and by the Korca Science and Engincering Foundation (Grant No. 98-(05-(0l-(1)-(1)l-3).

\section{References}

1. Bonas-Laurent. H.: Castellan. A.: Desvergne. J. P.: Lapouyade. R. Chem. Soc Rov 2000. 29.43.

2. Tran-Cong. Q. Photochomic Reactions, Polarization-Indaced.

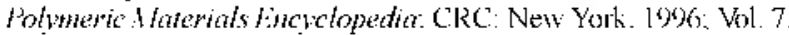

3. Dabestani, R. Fillis. K. I. Sigman. M. I. J. Photochem. Photohiol. 1. (Them. 1995. 86.231

4. Deng. Gi.: Sakaki. T.: Shinkai. S. J. Polm. Sci. Pont A. Polym. (7nm 1993. 31. 1915.

5. Tsudera. T.: Ikeda. A.: Shinkai. S. Tetrofkdon 1997. 53. 13609.

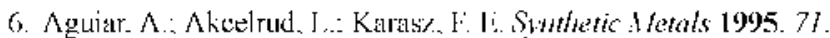
2189

7. Suruki. H.: Satoh. S.: Kimata. Y.: Kunvama. A. Chem. Lett. 1995. 451 .

8. Satol. S.: Suzuki. H.: Kimata. Y.: Kuriyama. A. Symthetic Metuls 1996. 79.97 .

9. Paul, S.: I Ialle, O.: Finsiedel. I .: Menges. B.: Mullen. K.: Knoll. W.: Mittler-Neher. S. Thim Solid Fiths 1996. 288.150.

10. Vogel. A. I. A Texthook of Practical (Organic Chemistry . 3rd ed.: Longman: London. 1973: p 740.

11. Bratschikov. C:: Karpuzova. P.: Müllen. K: Klapper. M.: Schopov. I. Polwher Balletim 2001. t6. 345 .

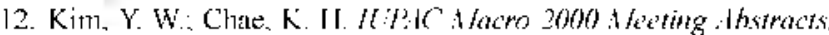
vol. 2: 38th Maeromolecular IIJPAC Srmposium. Polish Chemical Societs: Warsaw, Poland, $20(0)$ p p 8.39

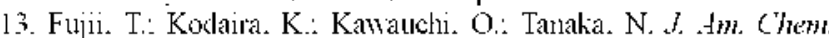
Soc. 1997. 101. 10631

14. Tung. C. H.: Guan. J. Q. J. Org. (7/kn. 1998. 63. 5857 . 